\title{
Granulocyte macrophage colony-stimulating factor is the main cytokine enhancing survival of eosinophils in asthmatic airways
}

\author{
C.S. Park, Y.S. Choi, S.Y. Ki, S.H. Moon, S.W. Jeong, S-T. Uh, Y.H. Kim
}

Granulocyte macrophage colony-stimulating factor is the main cytokine enhancing survival of eosinophils in asthmatic airways. C.S. Park, Y.S. Choi, S.Y. Ki, S.H. Moon, S.W. Jeong, S-T. Uh, Y.H. Kim. (OERS Journals Ltd 1998.

ABSTRACT: Interleukin (IL)-3, IL-5 and granulocyte macrophage colony-stimulating factor (GM-CSF) prolong the survival of eosinophils, which are conspicuous in asthmatic airways, but it is still controversial which one plays a major role in enhancing the survival of eosinophils in asthmatic airways.

The role of these cytokines in airway eosinophilia was investigated using bronchoalveolar lavage (BAL) fluids from 11 symptomatic and nine asymptomatic patients with asthma and eight normal subjects. Eosinophil survival-enhancing activity (ESEA) was measured by a numerical change in viable eosinophils isolated from the peripheral blood of atopic patients and cultured with BAL fluids. ESEA was characterized by neutralization with antibodies to IL-3, IL-5 and/or GM-CSF. The differential count of BAL cells was achieved using Diff-Quik stain. T-cell subsets and activated Tcells were analysed by flow cytometry with dual stain using monoclonal antibodies to CD3, CD4, CD8 and CD25.

ESEA was detected in eight of 11 BAL fluids of symptomatic asthma, but not in those of normal controls or asymptomatic asthmatics. In six symptomatic asthmatics, the mean percentage of inhibition in ESEA by anti-GM-CSF was higher than that of anti-IL-5 as well as anti-IL-3 (p<0.05). A mixture of antibodies to IL-3, IL-5 and GMCSF totally inhibited the ESEA in four cases. The ESEA correlated with the percentage of eosinophils $(p<0.05)$ and that of CD25 $(+)$ CD4 lymphocytes $(p<0.05)$ of BAL cells.

In conclusion, granulocyte macrophage colony-stimulating factor, rather than interleukin-3 or $\mathbf{- 5}$, is associated with eosinophil survival-enhancing activity inside the airways of symptomatic asthmatics. The activation of CD4 lymphocytes is related to the elevation of such activity.

Eur Respir J 1998; 12: 872-878.

Bronchial asthma is characterized as an eosinophilic inflammatory airway disease. Eosinophils increase in bronchoalveolar lavage (BAL) and the bronchial mucosa of symptomatic patients with asthma [1, 2]. Eosinophils are also prominent among BAL cells during the late asthmatic reaction after bronchial challenge with specific allergens $[3,4]$. Eosinophils release mediators to induce airway inflammation and hyperreactivity [5]. Processes of adherence, chemotaxis and prolongation of survival determine the infiltration of eosinophils into the tissues. Once eosinophils are recruited into the bronchial mucosa from vessels, the prolongation of survival may be a major determinant of the infiltration of eosinophils. Among the eosinophil-active cy-tokines, interleukin (IL)-3, IL-5 and granulocyte macrophage colony-stimulating factor (GM-CSF) are able to prolong the survival of eosinophils [6-9]. Messenger ribonucleic acid (mRNA) and proteins of IL-3, IL-5 and GM-CSF are expressed in the bronchial tree after specific allergen challenges $[10,11]$ and during symptomatic periods of asthma [12-15]. Sources of each of these cytokines are diverse in the asthmatic bronchial tree. Although Tlymphocytes produce IL-5, IL-3 and GM-CSF [10, 14, $15]$, epithelium $[13,16]$ and macrophages $[14,16]$ also produce GM-CSF and IL-3.
Division of Allergy and Respiratory Medicine, Dept of Internal Medicine, Soonchunhyang University Hospital, Seoul and Chunan, Korea

Correspondence: C.S. Park

Soonchunhyang University Hospital 657, Hannam-dong

Youngsan-ku

Seoul, 140-743

Korea

Fax: 8227925812

Keywords: Bronchoalveolar lavage fluid eosinophils

granulocyte macrophage colony-stimulating factor

interleukin-3

interleukin-5

T-lymphocytes

Received: May 51997

Accepted after revision July 21998

This work was supported by a grant No KOSEF 96-0403-07-01-3 from the Korean Science and Engineering Foundation
There is controversy about cytokines enhancing the survival of eosinophil in asthmatic airways. In a study using BAL fluids after specific allergen challenges [17], IL-5 was mainly associated with BAL eosinophilia with a minor contribution by GM-CSF. However, a study using sputum obtained from symptomatic asthmatics showed a contradictory result [18]. Thus, eosinophil survival-enhancing activity (ESEA) in BAL fluids was compared between asthmatic patients and normal subjects and the ESEA was characterized to identify the main eosinophil-active cytokine in terms of the prolongation of eosinophil survival. In addition, the relationship between ESEA and proportions of activated T-lymphocytes of BAL cells, as a source of eosinophil-active cytokines, was analysed.

\section{Materials and methods}

\section{Subjects}

This study included 11 symptomatic patients and nine asymptomatic patients with asthma and eight normal control subjects. They were all nonsmokers. Age and sex were matched between the groups. All asthmatic subjects met the criteria of the American Thoracic Society [19] on the 
basis of clinical symptoms and physical examination. Each patient showed an airway reversibility documented by an inhalant bronchodilator-induced improvement of $>15 \%$ in forced expiratory volume in one second (FEV1) and/or airway hyperreactivity measured by the histamine challenge test. The symptomatic patients had asthmatic symptoms from days to several weeks before BAL. The asymptomatic patients were previously diagnosed as having bronchial asthma, but were free from asthmatic symptoms during the 4 weeks before BAL.

Atopy was determined by the presence of a positive immediate skin response or specific immunoglobulin E (IgE) in serum to one or more allergens including dust mites, cat fur, dog fur, cockroaches and grass pollens. Six symptomatic patients, five asymptomatic patients and four control subjects showed atopy. All subjects showed no evidence of respiratory infections during the 4 weeks before the study. FEV1, forced vital capacity (FVC) and peak expiratory flow rate (PEFR) were measured 2 days before BAL. The symptomatic patients had significantly lower values of FEV1, FVC and PEFR than the asymptomatic patients and normal subjects. Airway reactivity was measured by the provocative concentration of histamine required to reduce FEV 1 by $20 \%$ of prechallenge value (PC20). The mean value of $\mathrm{PC} 20$ histamine was significantly lower in both the symptomatic and the asymptomatic patients with asthma than that of the normal subjects (table 1). This study was performed with the approval of the Ethics Committee of Soonchunhyang University Hospital and informed written consent was obtained from all study subjects.

\section{Bronchoalveolar lavage and preparation of fluids}

No patient with bronchial asthma had ever used inhaled or systemic steroids before the study. In symptomatic patients with asthma, BAL was carried out after clinical improvement by treatment with an i.v. infusion of aminophylline $\left(5 \mathrm{mg} \cdot \mathrm{kg}^{-1} \cdot \mathrm{day}^{-1}\right)$ and inhalation of aqueous $\beta_{2^{-}}$ agonist (salbutamol 6-10 mg.day-1). Both aminophylline and salbutamol were stopped $12 \mathrm{~h}$ before BAL. BAL was performed with fibreoptic bronchoscopy (Olympus B2-10, Olympus, Tokyo, Japan) after premedication with atropine and diazepam and local anaesthesia with $20 \mathrm{~mL}$ of $2 \%$ lidocaine. Each subject inhaled $200 \mu \mathrm{g}$ of salbutamol from a metered-dose inhaler before bronchoscopy. Lavage was performed by instilling four aliquots $(50 \mathrm{~mL}$ each) of

Table 1. - Profiles of the study populations

\begin{tabular}{lccc}
\hline & NC & SBA & Asym BA \\
\hline Age yrs* & $35(25-52)$ & $34(24-65)$ & $33(28-58)$ \\
Sex M/F & $5 / 3$ & $6 / 5$ & $6 / 3$ \\
FEV1 \% pred & $96.5 \pm 10.3$ & $72.5 \pm 4.5^{\sharp}$ & $88.5 \pm 4.8$ \\
FVC \% pred & $98.5 \pm 9.7$ & $76.7 \pm 8.1^{\#}$ & $96.7 \pm 5.7$ \\
PEFR \% pred & $91.4 \pm 7.9$ & $69.0 \pm 4.6^{\#}$ & $86.2 \pm 6.6$ \\
PC20 mg.mL - $-1 \ddagger^{\ddagger}$ & $17.4 \pm 4.3$ & $0.86 \pm 0.6 \S$ & $1.43 \pm 0.7 \S$ \\
Atopy n & 4 & 6 & 5
\end{tabular}

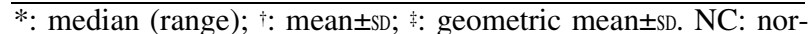
mal controls; SBA: symptomatic bronchial asthma; Asym BA: asymptomatic bronchial asthma; FEV1: forced expiratory volume in one second; FVC: forced vital capacity; PEFR: peak expiratory flow rate; $\mathrm{PC} 20$ : provocative concentration of histamine causing a $20 \%$ fall in FEV1. \#: $\mathrm{p}<0.01$ versus $\mathrm{NC}$ and Asym BA; $s: \mathrm{p}<0.01$ versus $\mathrm{NC}$. sterile and warm saline at the right middle lobe. The lavage fluid was withdrawn immediately by gentle suction with negative pressure below $50 \mathrm{mmHg}$ and collected in polyethylene tubes on ice. After filtering through a layer of gauze, the cell number was counted in a haemocytometer. BAL fluids were separated from cell pellets by centrifugation at $500 \times \mathrm{g}$ for $5 \mathrm{~min}$ at $4^{\circ} \mathrm{C}$. Cell pellets were brought to a concentration of $2 \times 10^{6}$ cells $\cdot \mathrm{mL}^{-1}$ for slide preparation and flow cytometry. Cytocentrifuge slides were air-dried, fixed in methanol and stained (Diff-Quik; American Scientific Products, Chicago, IL, USA). Five hundreds of leukocytes were enumerated for differential counts. The BAL fluids of symptomatic patients with more than $3 \%$ eosinophils in BAL cells were selected for measurement of ESEA. The lavage fluids were concentrated 100-fold using a Centricon-10 concentrator (Amicon Co., Beverly, MA, USA) with a molecular weight cut-off of $10,000 \mathrm{kDa}$. No complications were experienced in any subjects during the BAL procedures.

\section{Purification of eosinophils}

Eosinophils were isolated from the peripheral blood of atopic patients by the discontinuous Percoll gradients method [20]. In brief, heparinized venous blood was sedimented with $5 \%$ dextran in $0.9 \% \mathrm{NaCl}$ at room temperature for $60 \mathrm{~min}$ to remove erythrocytes. A leukocyte-rich layer was aspirated, centrifuged at $300 \times \mathrm{g}$ for $10 \mathrm{~min}$, then washed twice in piperazine diethanesulphonic acid (PIPES) buffer (25 nM PIPES, $110 \mathrm{mM} \mathrm{NaCl}, 5 \mathrm{mM} \mathrm{KCl}, 40 \mathrm{mM}$ $\mathrm{NaOH}$ and $5.4 \mathrm{mM}$ glucose). Percoll and PIPES buffer were mixed to obtain solutions of the following density (in $\left.\mathrm{g} \cdot \mathrm{mL}^{-1}\right): 1.100(1.5 \mathrm{~mL}), 1.090(3 \mathrm{~mL}), 1.085(3 \mathrm{~mL})$, and $1.080(3 \mathrm{~mL})$. The osmolarity of Percoll ranged from 280-310 mosmol. $\mathrm{kg}^{-1}$ and the $\mathrm{pH}$ was 7.4 . These were then layered at the indicated volumes in $140 \times 10 \mathrm{~mm}$ polystyrene tubes. Cells were suspended in $2 \mathrm{~mL}$ of the Percoll solution $\left(1.070 \mathrm{~g} \cdot \mathrm{mL}^{-1}\right)$, layered on the top of the gradients and centrifuged at $1,600 \times \mathrm{g}$ for $30 \mathrm{~min}$ at $4^{\circ} \mathrm{C}$. The fractions containing eosinophils were pooled and washed twice in RPMI-1640 medium. The eosinophil-enriched fractions were incubated with CD16 monoclonal antibody (MAb)-conjugated microbeads (Miltenyi Biotec, BelgischGladbach, Germany) and a negative selection was conducted with a magnetic cell separator (MACS System; Becton-Dickinson, Mountain View, CA, USA) to remove the contaminating neutrophils [21]. The purity of eosinophils was $>98 \%$, as determined by light-microscopic examination of cytocentrifuge slides prepared with Diff-Quik stain. Viability of eosinophils was determined by exclusion of propidium iodide $\left(2 \mu \mathrm{g} \cdot \mathrm{mL}^{-1}\right)$ with a flow cytometer (FACscan; Becton-Dickinson) [22]. The viability was $>98 \%$ at the beginning of culture.

\section{Measurement of eosinophil survival-enhancing activity in bronchoalveolar lavage fluids}

ESEA was measured as described previously [8, 17, 18]. In brief, $1 \times 10^{6}$ eosinophils were suspended in $1 \mathrm{~mL}$ of RPMI-1640 containing $1 \%$ human serum albumin (tissue culture medium (TCM)). Cell suspensions $(150 \mu \mathrm{L})$ were mixed with $75 \mu \mathrm{L}$ of the unconcentrated BAL fluids, 
the 100-fold concentrated BAL fluids (33-fold, final concentration), IL-3, IL-5, GM-CSF (Genzyme, Cambridge, MA, USA) and TCM in 96-well flat-bottomed tissue-culture plates, then incubated at $37^{\circ} \mathrm{C}$ in a $5 \% \mathrm{CO}_{2}$ humidified chamber. The viability of eosinophils was measured again at $72 \mathrm{~h}$ of culture as described above. Survival of eosinophils was calculated as the number of viable cells at $72 \mathrm{~h}$ of culture divided by that at the start of culture.

To characterize eosinophil-active cytokines in BAL fluids, the 100-fold concentrated BAL fluids were pretreated with MAb for $1 \mathrm{~h}$ at $4^{\circ} \mathrm{C}$. The MAb included mouse antihuman GM-CSF $\left(10 \mu \mathrm{g} \cdot \mathrm{mL}^{-1}\right.$, final concentration), antihuman IL-3 $\left(50 \mu \mathrm{g} \cdot \mathrm{mL}^{-1}\right)$ and anti-human IL-5 $\left(10 \mu \mathrm{g} \cdot \mathrm{mL}^{-1}\right.$, Genzyme). Each MAb was specific for its respective cytokine and was not cross-reactive with other cytokines. Cell suspensions $(150 \mu \mathrm{L})$ were mixed with $75 \mu \mathrm{L}$ of the MAb-treated BAL fluids or TCM, then incubated at $37^{\circ} \mathrm{C}$ in a $5 \% \mathrm{CO}_{2}$ humidified chamber for $72 \mathrm{~h}$. All experiments were carried out in triplicate. The inhibition percentage of ESEA by anti-cytokine MAb was determined by the following formula:

Inhibition $(\%)=(\mathrm{ES}(\mathrm{BAL})-\mathrm{ES}(\mathrm{TCM}))-(\mathrm{ES}$ (BAL plus anti-cytokine MAb) - ES (TCM))

$$
\text { ES (BAL) - ES (TCM) }
$$

where ES is the percentage of eosinophil survival.

\section{Expression of low-affinity interleukin-2 receptor on T-cell} subsets of bronchoalveolar lavage cells

BAL cells were washed twice and suspended in $\mathrm{Ca}^{2+}$ and $\mathrm{Mg}^{2+}$-free phosphate-buffered saline (PBS) containing $0.1 \%$ bovine serum albumin and $0.2 \%$ sodium azide. To enumerate the expression of low-affinity receptors for IL2 (CD25) on T-lymphocyte subsets, dual immunofluorescence staining with MAbs was performed according to the standard method recommended by the Becton-Dickinson Monoclonal Center. Aliquots containing $1 \times 10^{6}$ cells were incubated for $30 \mathrm{~min}$ at $4{ }^{\circ} \mathrm{C}$ in the saturating concentrations of MAbs conjugated with fluorescein isothiocya-nate (FITC) or phycoerythrin. Each MAb for CD3 (Leu-2), CD4 (Leu-4) and CD8 (Leu-3) was a conjugated form with FITC. MAb for CD25 (anti-Tac) was a conjugated form with phycoerythrin (Becton-Dickinson). The surface immunofluorescence was analysed with a FACscan (BectonDickinson). The cells were excited with a 488-mm argon laser. The filter set to separate the two signals was recommended by the manufacturer for FITC and phycoerythrin. Each sample was measured up to 10,000 cells. The data were collected and analysed using the Consort 40 program (Becton-Dickinson).

\section{Statistics}

Differences between independent samples were compared using the nonparametric Kruskal-Wallis H-test for the continuous data. When found significant, the MannWhitney U-test was applied to compare the difference between two samples. The Wilcoxon signed rank test was applied to the changes of ESEA in the concentrated BAL fluids by pretreatment with MAbs. The relationship between two parameters was studied using Spearman's rank correlation. The difference was considered significant when $\mathrm{p}$-value $<0.05$. The results were expressed as means \pm SEM unless stated otherwise.

\section{Results}

Eosinophil survival-enhancing activity in bronchoalveolar lavage fluids

Survival of eosinophils decreased rapidly by $72 \mathrm{~h}$ of culture without eosinophil-active cytokines. IL-5, GMCSF and IL-3 significantly increased the survival of eosinophils in a dose-dependent manner from $1 \mathrm{pg} \cdot \mathrm{mL}^{-1}$ to 10 ng. $\mathrm{mL}^{-1}$ of each cytokine when compared with that by TCM alone. The order of potency to enhance survival was IL-5 > GM-CSF > IL-3 (at the same concentrations) (fig. 1). BAL fluids were concentrated because ESEA was not detected in the unconcentrated BAL fluids of seven symptomatic and five asymptomatic patients with asthma. To examine the change in ESEA of IL-3, IL-5 and GM-CSF by the concentrating procedure with the ultrafiltration membrane, the ESEA of each cytokine $\left(1 \mathrm{ng} \cdot \mathrm{mL}^{-1}\right.$ each) was compared before and after processing with a Centricon10 . The recovery rate of the ESEA for each cytokine was $>90 \%$.

The concentrated BAL fluids from eight of the 11 symp-tomatic patients enhanced the survival of eosinophils. The mean value of ESEA in symptomatic asthma was significantly higher than that of TCM $(31.2 \pm 5.5 \mathrm{ver}$ sus $8.1 \pm 0.5 \%, \mathrm{p}<0.001)$. In contrast, the values of normal subjects $(9.3 \pm 1.0 \%)$ and asymptomatic patients $(10.4 \pm 0.9 \%)$ did not show an enhanced survival of eosinophils compared with TCM ( $\mathrm{p}>0.05)$. The symptomatic patients had a significantly higher mean value of ESEA than that of asymptomatic patients $(\mathrm{p}<0.001)$ and that of normal controls $(p<0.001)$ (fig. 2$)$. The mean value of atopic patients was not significantly different from that of nonatopic patients in the symptomatic asthma group (30.8 \pm 8.7 versus $31.4 \pm 5.2 \%, \mathrm{p}>0.05)$.

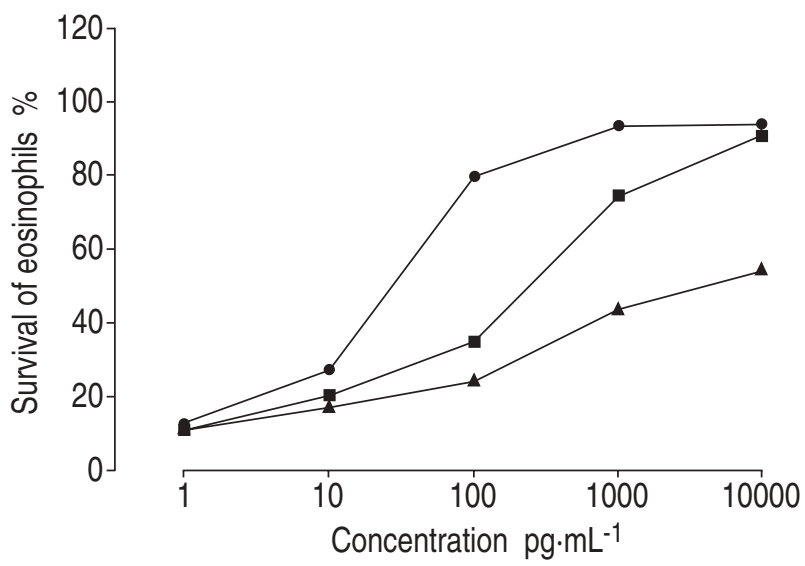

Fig. 1. - Eosinophil survival-enhancing activity of interleukin (IL)-5 $(\bullet)$, granulocyte macrophage colony-stimulating factor (GM-CSF; $\mathbf{0})$ and IL-3 (A) in vitro. Eosinophil survival was measured at $72 \mathrm{~h}$ of culture with IL-5, GM-CSF and IL-3 (1 pg. $\mathrm{mL}^{-1}$ to $\left.10 \mathrm{ng} \cdot \mathrm{mL}^{-1}\right)$. Each cytokine significantly increased the survival of eosinophils in a dosedependent manner. 


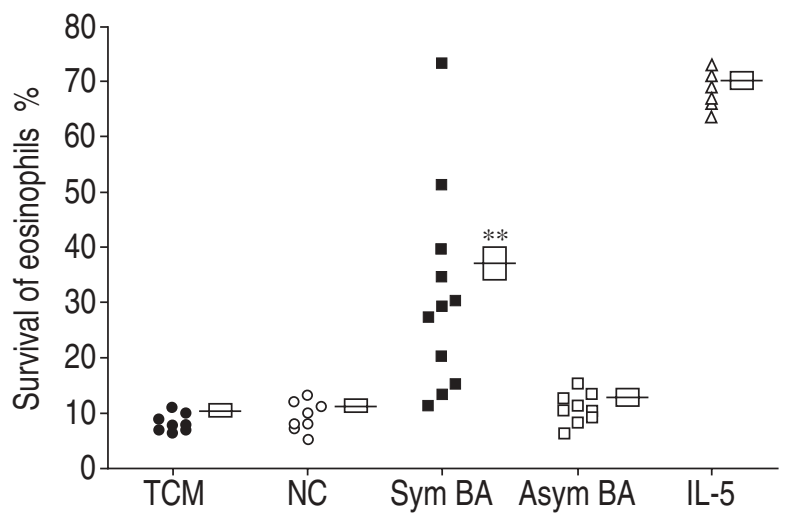

Fig. 2. - Eosinophil survival-enhancing activity in concentrated bronchoalveolar lavage (BAL) fluids from the study subjects. (Individuals and means \pm SEM.) The concentrated BAL fluids from the symptomatic bronchial asthma patients (Sym BA) significantly enhanced the survival of eosinophils when compared with tissue culture medium (TCM), those from the normal controls (NC) and the asymptomatic patients (Asym BA). Interleukin (IL)-5 (1 ng. $\left.\mathrm{mL}^{-1}\right)$ was used as a positive control. **: $\mathrm{p}<0.001$ versus TCM, NC and Asym BA.

To examine the effect of BAL fluids on ESEA of IL-5, IL-3 and GM-CSF, the concentrated BAL fluids of a normal subject (ESEA: $11.2 \%$ ), a symptomatic patient (ESEA: $51.2 \%$ ) and an asymptomatic patient (ESEA: 13.2\%) were mixed with IL-5, IL-3 and GM-CSF (1 ng.mL-1), then the ESEA was compared with that observed with the same cytokine in TCM only (ESEA: 10.8\%). The concentrated BAL fluid of the symptomatic patient significantly augmented the ESEA of IL-5, IL-3 and GM-CSF (fig. 3), but neither the BAL from a normal subject nor from an asymptomatic patient changed the ESEA of each cytokine (data not shown).

Identification of eosinophil-active cytokines in bronchoalveolar lavage fluids of the symptomatic patients with asthma

BAL fluids of six symptomatic patients with high ESEA (27-73\%) were selected for the blocking study. Pretreat-

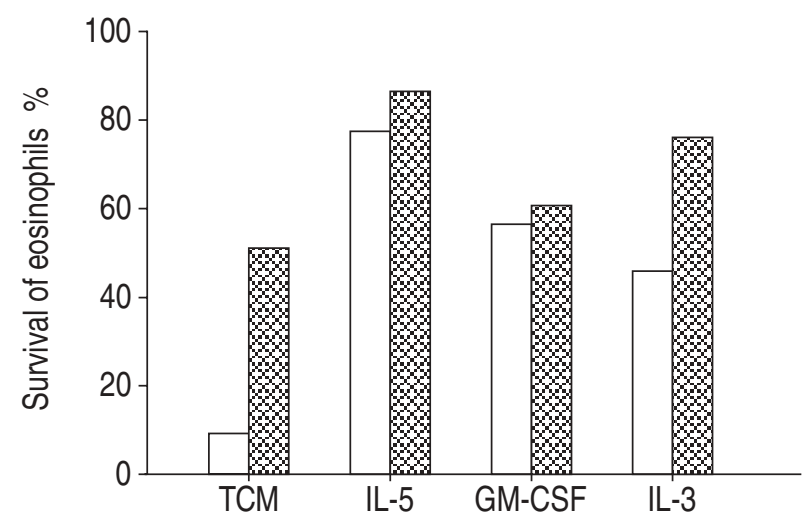

Fig. 3. - Effect of concentrated bronchoalveolar lavage (BAL) fluid on the eosinophil survival-enhancing activity (ESEA) of interleukin (IL)-5, IL-3 and granulocyte macrophage colony-stimulating factor (GM-CSF). A concentrated BAL fluid of symptomatic patients (ESEA: 51.2\%) was mixed with IL-5, IL-3 and GM-CSF (1 ng.mL-1), then the ESEA was compared with that observed with the same cytokine in tissue culture medium (TCM) only (ESEA: $10.8 \%$ ). $\square$ : without BAL fluid; $\mathbb{} \times$ : with BAL fluid. The concentrated BAL fluid significantly augmented the ESEA of IL-5, IL-3 and GM-CSF.

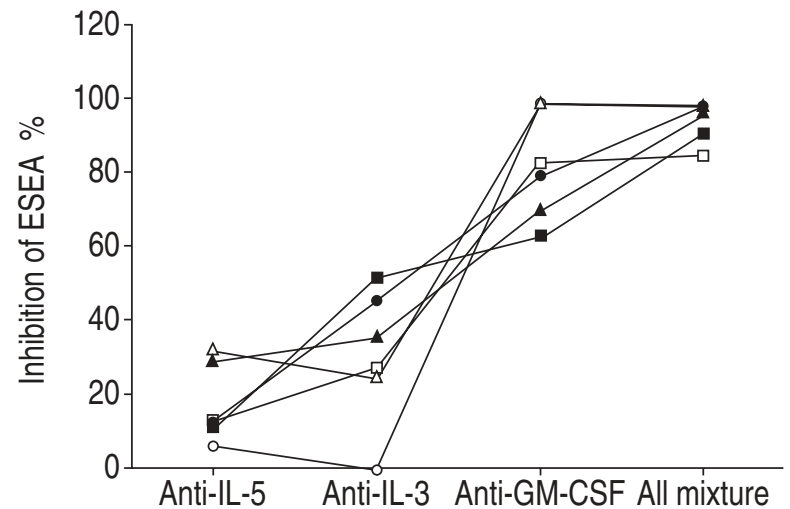

Fig. 4. - Inhibition of the eosinophil survival-enhancing activity (ESEA) in bronchoalveolar lavage (BAL) fluids from symptomatic patients by monoclonal antibodies to interleukin (IL)-5, IL-3 and granulocyte macrophage colony-stimulating factor (GM-CSF). Pretreatment with anti-GM-CSF completely neutralized the ESEA in two of six patients. The mean percentage of inhibition of ESEA was $83.3 \pm 7.8 \%$ by anti-GM-CSF, $31.6 \pm 7.7 \%$ by anti-IL-3 and $14.4 \pm 4.3 \%$ by anti-IL-5. A mixture of anti-IL-5, anti-IL-3 and anti-GM-CSF completely inhibited the ESEA from four of six cases.॰,,$\Delta$, atopic asthma; $\bullet, \mathbf{\bullet}, \mathbf{\Delta}$ : nonatopic asthma

ment with antibodies to IL-5, IL-3 or GM-CSF significantly reduced the ESEA in the concentrated BAL fluids (fig. 4). Pretreatment with anti-GM-CSF antibody completely neutralized the ESEA in two of six cases. The mean percentage of inhibition was $83.3 \pm 7.8 \%$ by anti-GM-CSF antibody, $31.6 \pm 7.7 \%$ by anti-IL-3 antibody and $14.4 \pm 4.3 \%$ by anti-IL- 5 antibody. The inhibitory percentage by anti-GM-CSF was significantly higher than that of both anti- IL-5 antibody and anti-IL-3 antibody $(p<0.05)$. However, there was no significant difference between the inhibition of ESEA by anti-IL-3 antibody and that by anti-IL-5 antibody ( $\mathrm{p}>0.05$ ). A mixture of antibodies for IL-5, IL-3 and GM-CSF totally inhibited the ESEA in four cases.

Cellular profiles of bronchoalveolar lavage cells and relationships with eosinophil survival-enhancing activity in the symptomatic patients with asthma

The symptomatic patients with asthma had greater percentages of eosinophils, neutrophils and lymphocytes among BAL cells compared with those of the normal subjects. The percentage of eosinophils was higher in the symptomatic patients than in the asymptomatic patients $(\mathrm{p}<0.01)$ (table 2). In the symptomatic patients, ESEA correlated significantly with the percentage of eosinophils ( $r=0.82$, $\mathrm{p}<0.01$ ) of BAL cells, but not with that of neutrophils ( $\mathrm{r}=$ $0.22, \mathrm{p}>0.05)$, lymphocytes $(\mathrm{r}=-0.06, \mathrm{p}>0.05)$ or macrophages $(r=-0.57, p>0.05)$. ESEA correlated significantly with the percentages of CD25(+)CD3 lymphocytes $(\mathrm{r}=0.78$, $\mathrm{p}<0.01)$ and CD25(+)CD4 lymphocytes $(\mathrm{r}=0.69, \mathrm{p}<0.05)$, but not with the percentages of either T-cell subsets or CD25(+)CD8 lymphocytes (table 3). The percentage of eosinophils correlated with the percentage of both CD25 $(+) \mathrm{CD} 3$ lymphocytes $(\mathrm{r}=0.81, \mathrm{p}<0.01)$ and $\mathrm{CD} 25(+) \mathrm{CD} 4$ lymphocytes $(r=0.77, p<0.05)$. ESEA of the symptomatic patients with asthma did not correlate significantly with PEFR ( $\mathrm{r}=-0.14, \mathrm{p}>0.05)$ FEV1 $\mathrm{r}=-0.18, \mathrm{p}>0.05)$ or $\mathrm{PC}_{20}$ $(\mathrm{r}=-0.21, \mathrm{p}>0.05)$. 
Table 2. - Cellular profiles of bronchoalveolar lavage cells

\begin{tabular}{|c|c|c|c|c|c|c|}
\hline & \multicolumn{2}{|r|}{$\mathrm{NC}$} & \multicolumn{2}{|r|}{ SBA } & \multicolumn{2}{|c|}{ Asym BA } \\
\hline Study number & & 7 & & 11 & & 9 \\
\hline Total number $\times 10^{6}$ & 19.3 & $(9.2-29.5)$ & 24.5 & $(12.3-48.6)$ & 19.2 & $(11.6-33.2)$ \\
\hline Recovery \% & 50.2 & $(38.7-62.8)$ & 46.3 & $(27.5-70.1)$ & 49.0 & $(35.3-55.2)$ \\
\hline Macrophages \% & 93.8 & (89.2-98.5) & 72.0 & $(65.1-89.9) * *$ & 90.6 & $(85.3-97.6)$ \\
\hline Lymphocytes \% & 4.2 & $(2.0-11.2)$ & 13.9 & $(4.4-43.9)^{\#}$ & 5.3 & $(3.2-13.2)$ \\
\hline Neutrophils \% & 0.9 & $(0.0-2.3)$ & 2.3 & $(0.4-11.8)^{\#}$ & 1.6 & $(0.1-3.3)$ \\
\hline Eosinophils \% & 0.8 & $(0.0-1.5)$ & 12.5 & $(4.4-50.4)+*$ & 3.2 & $(0.6-6.8)^{\#}$ \\
\hline
\end{tabular}

Values are expressed as median (range). NC: normal controls; SBA: symptomatic bronchial asthma; Asym BA: asymptomatic bronchial asthma. **: $\mathrm{p}<0.01$ versus $\mathrm{NC}$ and Asym BA; \#: $\mathrm{p}<0.01 ;+: \mathrm{p}<0.001$ versus $\mathrm{NC}$; *: $\mathrm{p}<0.05$ versus Asym BA.

\section{Discussion}

This study confirmed that the BAL fluids of symptomatic patients with asthma significantly increased the survival of eosinophils in vitro. In the measurement of ESEA, concentration of the BAL fluids was necessary because ESEA was not detected in the unconcentrated BAL fluids. Concentration ratios vary among the studies measuring ESEA. OнNISн et al. [17] observed ESEA in the 4-fold diluted BAL fluids, which were obtained at $48 \mathrm{~h}$ after segmental allergen challenges. In contrast, in a study of symptomatic patients with nocturnal asthma, JARJOUR and Busse [23] did not find ESEA in the 10-fold concentrated BAL fluids. One explanation for the lack of ESEA in the study of JARJOUR and BusSE [23] is that the BAL fluids might not have been concentrated enough for the detection of ESEA. The other possibility is the presence of in-hibitory factors in BAL fluids. OHNISH et al. [24] observed an inhibitory activity with a molecular weight $<3,000 \mathrm{kDa}$ in BAL fluids. Lidocaine was suggested to be the inhibitor because of its ability to inhibit the survival of eosinophils in vitro. In the present study, Centricon-10 with a molecular weight cut-off of $10,000 \mathrm{kDa}$ was used to concentrate the BAL fluids. Thus, lidocaine would be removed from the BAL fluids, and no inhibitory effect was observed in the concentrated BAL fluids on the ESEA of IL-3, IL-5 and GM-CSE. Another possibility is that a heavy exposure to allergens in cases of segmental allergen challenges might produce a greater amount of cytokines than the natural aggravation of asthma in the patients of this study.

It was demonstrated that GM-CSF was the major cytokine responsible for the ESEA in the BAL fluids of symptomatic patients. A similar neutralization method was used with monoclonal antibodies for IL-3, IL-5 and GM-CSF

Table 3. - Correlation coefficients between eosinophil survival-enhancing activity (ESEA) and bronchoalveolar lavage cells in symptomatic patients with bronchial asthma $(n=11)$

\begin{tabular}{lrrrrr}
\hline & \multicolumn{2}{c}{ ESEA } & & \multicolumn{2}{c}{ Eosinophils } \\
\cline { 2 - 3 } & $\mathrm{r}$ & $\mathrm{p}$ & & $\mathrm{r}$ & $\mathrm{p}$ \\
\hline Eosinophils & 0.82 & 0.002 & & & \\
Monocytes & -0.57 & 0.068 & & -0.81 & 0.002 \\
Neutrophils & 0.22 & 0.520 & & 0.31 & 0.360 \\
Lymphocytes & -0.06 & 0.896 & & 0.16 & 0.642 \\
CD3 lymphocytes & -0.13 & 0.719 & & 0.19 & 0.591 \\
CD25(+)CD3 & 0.78 & 0.008 & & 0.81 & 0.005 \\
CD4 lymphocytes & 0.52 & 0.124 & & 0.39 & 0.256 \\
CD25(+)CD4 & 0.69 & 0.028 & & 0.77 & 0.010 \\
CD8 lymphocytes & -0.39 & 0.266 & & -0.09 & 0.802 \\
CD25(+)CD8 & 0.21 & 0.266 & & 0.27 & 0.454 \\
\hline
\end{tabular}

as described in the other studies $[17,18,23,24]$. However, OHNISH et al. [17] reported that IL-5 was mainly associated with ESEA in BAL fluids of the late response following segmental bronchial provocation, with a small contribution from GM-CSF. The discrepancy between the results may originate from the different backgrounds of the study populations. Their study subjects suffered from allergic rhinitis without bronchial hyperreactivity, whereas symptomatic asthma was employed in this present study. In the studies employing patients with symptomatic asthma, OHNIsH et al. [24] observed that IL-5 was a predominant eosiniphil-active cytokine in diluted BAL fluids from some of the patients. In contrast, ADACHI et al. [18] found that GM-CSF was primarily associated with ESEA, with a partial contribution from IL-5 in diluted sputum of symptomatic asthmatics, which was consistent with the present result. We cannot explain the causes of the different results between these studies.

Eosinophil-active cytokines are synthesized by a variety of cells in the bronchial tree. GM-CSF and IL-3 are produced by T-lymphocytes, epithelium $[13,16]$ and monocytes [25] in the bronchial mucosa. IL-5 is derived from T-cells and mast cells in the bronchial tree $[12,14]$. Eosinophils also produce IL-5 and GM-CSF [26]. Bronchial myofibro-blasts prolong eosinophil survival by tumour necrosis factor- $\alpha$ and IL-1-mediated synthesis of GM-CSF [27]. The ESEA correlated with the percentage of eosinophils of BAL cells, but not with those of other inflammatory cells. This suggests that the ESEA of symptomatic patients is specific for eosinophils. A significant correlation was also observed between the percentage of CD25(+)CD4 lymphocytes and the ESEA, which means that the activated T-lymphocytes might be a source of the ESEA. The activated T-helper cells are evidently increased in the peripheral circulation and the bronchial tree of symptomatic asthmatics, $[15,16,28]$. They generate eosinophil-active cytokines, such as IL-3, IL-5 and GM-CSF $[14,29]$. In a study using the T-cell line of BAL cells [30], polyclonal CD4+ T-cell lines from asthmatics secreted significantly elevated quantities of both IL-5 and GM-CSF compared with lines from atopic and nonatopic controls. These data partially support the present result of a correlation between the percentage of CD25(+)CD4 lymphocytes and the ESEA in the BAL of symptomatic patients with asthma.

Investigation of local expression of eosinophil-active cytokines in the mucosa is also an important way in which to reveal the pathogenesis of asthma. In a study investigating $\alpha$-IL-5 receptor mRNA expression in bronchial mucosa [31], EG2-positive eosinophils were the major cells positive for $\alpha-$ IL-5 receptor mRNA in asthmatics. This 
provides strong evidence that IL-5 may play an important role in stimulating eosinophils in the mucosa of asthmatics via the specific $\alpha$-subunit of its receptor. In a study by KoTsImBos et al. [32], the number of $\alpha$-GM-CSF recep- tor mRNA-positive cells correlated with the number of CD68-positive macrophages in the lamina propria of patients with asthma, but not with the number of EG2-positive cells. However, a co-localization study revealed that $15 \%$ of $\alpha$-GM-CSF receptor mRNA-positive cells were positive for major basic protein. This suggests that GM-CSF is partially responsible for eosinophil survival in the lamina propria. The localization of IL-5, GM-CSF and IL-3 in the bronchial mucosa of symptomatic asthmatics was investigated using an immunohistochemical stain [33]. The main site of IL-5 expression was on the mononuclear cells of the lamina propria, whereas IL-3 and GM-CSF were expressed mainly on the epithelium. The predominant expression of GM-CSF on the epithelium was reported by Sousa et al. [13] using hue saturation intensity colour image analysis. They observed that the epithelial cells of asthmatic subjects were stained significantly more with anti-GM-CSF antibody than those from normal subjects. In the subepithelial connective tissue, there was some staining in leukocytes and blood vessels, but this was not usually as extensive as staining of the epithelium.

These data suggest that granulocyte macrophage colonystimulating factor synthesized predominantly by the epithelium on the basement membrane may permeate into the bronchial lumen more easily than interleukin- 5 synthesized in the lamina propria below the basement membrane. This may explain the result that granulocyte macrophage colony-stimulating factor was the main eosinophil survival-enhancing cytokine in the bronchoalveolar lavage fluids of symptomatic asthmatics, rather than interleukin-5. Interleukin-5 may have an influence on the survival of eosinophils, mainly in the lamina propria, and granulocyte macrophage colony-stimulating factor mainly in the epithelial layer and bronchial lumen. To explain the exact process of eosinophil infiltration into the airway of symptomatic asthmatics, a quantitative measurement of eosinophil-active cytokines at the level of individual cells in the asthmatic bronchial tree would be required.

Acknowledgements: The authors thank M.R. Lee and U.Y. Kim for technical assistance in the preparation of eosinophils and flow cytometry.

\section{References}

1. Bousquet J, Chanez P, Lacoste JY, et al. Eosinophilic inflammation in asthma. N Engl J Med 1990; 323: 10331039.

2. Azzawi M, Bradley B, Jeffery PK, et al. Identification of activated T-lymphocytes and eosinophils in bronchial biopsies in stable atopic asthma. Am Rev Respir Dis 1990; 142: 1407-1413.

3. De Monchy JGR, Kauffman HF, Venge P, et al. Bronchoalveolar eosinophilia during allergen-induced late asthmatic reactions. Am Rev Respir Dis 1985; 131: 373-376.

4. Metzger WJ, Zavala D, Richerson HB, et al. Local allergen challenge and bronchoalveolar lavage of allergic asthmatic lungs: description of the model and local airway inflammation. Am Rev Respir Dis 1987; 135: 433-440.

5. Flavahan NA, Slifman NR, Gleich GJ, Vanhoutte PM.
Human eosinophil major protein causes hyperreactivity of respiratory smooth muscle: role of the epithelium. Am Rev Respir Dis 1988; 138: 685-688.

6. Clutterbuck EJ, Hirst EMA, Sanderson CJ. Human interleukin-5 (IL-5) regulates the production of eosinophils in human bone marrow cultures: comparison and interaction with IL-1, IL-3, IL-6 and GM-CSF. Blood 1989; 73: 1504-1512.

7. Yamaguchi Y, Hayashi Y, Sugama Y, et al. Highly purified murine interleukin-5 (IL-5) stimulates eosinophil function and prolongs in vitro survival: IL-5 as an eosinophil che-motactic factor. J Exp Med 1988; 167: 17371742

8. Tai PC, Sun L, Spry CJF. Effect of IL-5, granulocytes/ macrophage colony-stimulating factor (GM-CSF) and IL3 on the survival of human blood eosinophils in vitro. Clin Exp Immunol 1991; 85: 312-316.

9. Yamaguchi Y, Suda T, Ohta S, Tominaga K, Miura Y, Kasahara T. Analysis of the survival of mature human eosinophils: interleukin-5 prevents apoptosis in mature human eosinophils. Blood 1991; 78: 2542-2547.

10. Virchow JC Jr, Walker C, Hafner D, et al. T cells and cytokines in bronchoalveolar lavage fluid after segmental allergen provocation in atopic asthma. Am J Respir Crit Care Med 1995; 151: 960-968.

11. Zangrilli JG, Shaver JR, Cirelli RA, et al. sVCAM-1 levels after segmental antigen challenge correlate with eosinophil influx, IL-4 and IL-5 production, and the late phase response. Am J Respir Crit Care Med 1995; 151: 1346-1353.

12. Hamid Q, Azzawi M, Ying S, et al. Expression of mRNA for interleukin-5 in mucosal biopsies from asthma. J Clin Invest 1991; 87: 1541-1546.

13. Sousa AR, Poston RN, Lane SJ, Nakhosteen JA, Lee TK. Detection of GM-CSF in asthmatic bronchial epithelium and decrease by inhaled corticosteroids. Am Rev Respir Dis 1993; 147: 1557-1561.

14. Robinson DS, Hamid Q, Ying S, et al. Predominant $\mathrm{TH}_{2}$-like bronchoalveolar T-lymphocyte population in atopic asthma. N Engl J Med 1992; 326: 298-304.

15. Walker C, Bode E, Boer L, Hansel TT, Blaser K, Virchow JC. Allergic and nonallergic asthmatics have distinct patterns of T-cell activation and cytokine production in peripheral blood and bronchoalveolar lavage. Am Rev Respir Dis 1992; 146: 109-115.

16. Mattoli S, Mattoso VL, Soloperto M, Allergra L, Fasoli A. Cellular and biochemical characteristics of bronchoalveolar lavage fluid in symptomatic nonallergic asthma. J Allergy Clin Immunol 1991; 87: 794-802

17. Ohnishi T, Kita H, Weiler D, et al. IL-5 is the predominant eosinophil-active cytokine in the antigen-induced pulmonary late-phase reaction. Am Rev Respir Dis 1993; 147: 901-907.

18. Adachi T, Motojima S, Hirata A, Fukuda T, Makino S. Eosinophil viability-enhancing activity in sputum from patients with bronchial asthma. Am J Respir Crit Care Med 1995; 151: 618-623.

19. American Thoracic Society. Standards for the diagnosis and treatment of patients with chronic obstructive pulmonary disease (COPD) and asthma. Am Rev Respir Dis 1989; 136: 225-244.

20. Gartner I. Separation of human eosinophils in density gradients of polyvinylpyrrolidone-coated silica gel (Percoll). Immunology 1980; 40: 113-136.

21. Miltenyi S, Pfluger S. High gradient magnetic cell sorting. In: Radbruch A, ed. Flow Cytometry and Cell Sorting. Hong Kong, Springer, 1992; pp. 141-152. 
22. Yokoyama WM. Flow cytometry analysis using the Becton Dickinson FACScan. In: Coligan JE, Kruisbeck AM, Margulies DH, et al. eds. Current Protocols in Immunology. New York, Green Publishing Associates and WileyInterscience, 1991; unit 5.4.

23. Jarjour NN, Busse WW. Cytokines in bronchoalveolar lavage fluid of patients with nocturnal asthma. Am J Respir Crit Care Med 1995; 152: 1474-1477.

24. Ohnishi T, Kita H, Mayeno AN, et al. Lidocaine in bronchoalveolar lavage fluid (BALF) is an inhibitor of eosinophil-active cytokines. Clin Exp Immunol 1996; 104: 325-331.

25. Girgis-Gabardo A, Kanai N, Denburg JA, Hargreave FE, Jordana M, Dolovich J. Immunocytochemical detection of granulocyte-macrophage colony-stimulating factor and eosinophil cationic protein in sputum cells. J Allergy Clin Immunol 1994; 93: 945-947.

26. Broide DH, Paine MM, Firestein GS. Eosinophils express interleukin 5 and granulocyte macrophage-colony stimulating factor mRNA at sites of allergic inflammation in asthmatics. J Clin Invest 1992; 90: 1414-1424.

27. Zang S, Mohammed Q, Burbidge A, Morland CM, Roche WR. Cell cultures from bronchial subepithelial myofibroblasts enhance eosinophil survival in vitro. Eur Respir J 1996; 9: 1839-1846.
28. Park CS, Lee SM, Uh ST, et al. Soluble interleukin-2 receptor and cellular profiles in bronchoalveolar lavage fluid from patients with bronchial asthma. J Allergy Clin Immunol 1993; 91: 623-633.

29. Nakamura Y, Ozaki T, Kamei T, et al. Increased granulocyte/macrophage colony-stimulating factor production by mononuclear cells from peripheral blood of patients with bronchial asthma. Am Rev Respir Dis 1993; 147: 87-91.

30. Till S, Li Baiqing, Durham S, et al. Secretion of the eosinophil-active cytokines interleukin-5, granulocyte/macrophage colony-stimulating factor and interleukin-3 by bronchoalveolar lavage CD4+ and CD8+ T-cell lines in atopic asthmatics, and atopic and non-atopic controls. Eur J Immunol 1995; 25: 2727-2731.

31. Yasruel Z, Humbert M, Kotsimbos C, et al. Membranebound and soluble $\alpha$ IL- 5 receptor mRNA in the bronchial mucosa of atopic and nonatopic asthmatics. Am J Respir Crit Care Med 1997; 155: 1413-1418.

32. Kotsimbos ATC, Humbert M, Minshall E, et al. Upregulation of GM-CSF-receptor in nonatopic asthma but not in atopic asthma. J Allergy Clin Immunol 1997; 99: 666672.

33. Park TW, G-I Lim, SH Moon, et al. Expression of IL-3, IL-5 and GM-CSF on the airway mucosa of asthmatics. $J$ Korean Soc Allergol 1995; 15: 482. 